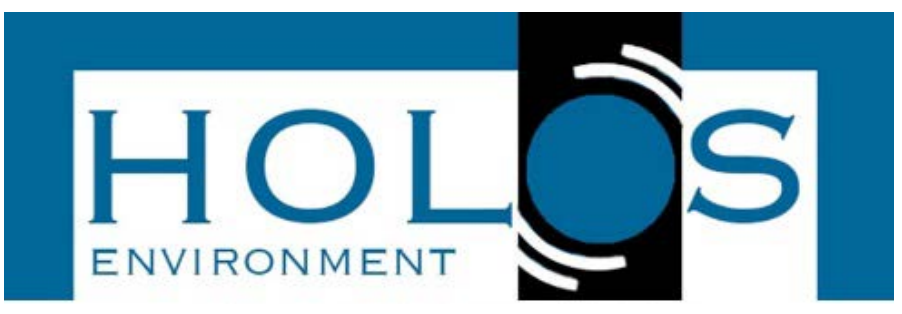

\title{
CARACTERIZAÇÃO DE BLENDAS DE AMIDO DE FEIJÃO MACÁÇAR, QUITOSANA E GLICEROL
}

\section{CHARACTERIZATION OF BLENDS OF MACÁÇAR BEAN STARCH, CHITOSAN AND GLYCEROL}

\author{
Djeson Mateus Alves da Costa ${ }^{1}$; Leidiane Araújo da Silva; \\ Mayra Thatiane Jerônimo de Lima ${ }^{1}$
}

Artigo recebido em: 26/04/2018 e aceito para publicação em: 09/10/2018.

DOI: http://dx.doi.org/10.14295/holos.v18i2.12290

Resumo: A presente pesquisa foi conduzida com o objetivo de extrair amido de feijão macáçar, quitosana de carapaças de camarão e avaliar as características das blendas de amido de feijão macáçarquitosana-glicerol, obtidas com diferentes combinações entre esses constituintes. Utilizou-se nas formulações para obtenção das blendas, amido de feijão macáçar ( $3 \mathrm{~g} / 100 \mathrm{~g}$ de solução) e diferentes porcentagens de quitosana e glicerol (0/20, 0/30, 5/20, 5/30, 10/20 e 10/30) respectivamente, em relação à quantidade de amido $(\mathrm{m} / \mathrm{m})$. As soluções foram vertidas em placas de Petri de vidro $(10 \mathrm{~mL})$ e secas em estufa com circulação de $a$ r, à $40^{\circ} \mathrm{C}$ por $24 \mathrm{~h}$. A matriz polimérica, amido de feijão macáçarquitosana-glicerol, apresentou ótima interação intermolecular pois produziu filmes com boa uniformidade, continuidade, manuseabilidade e transparência $(74,1562 \pm 4,8330 \%)$. Os filmes obtidos são adequados para embalagens transparentes de produtos desidratados e com baixo teor de umidade, os quais requerem maior atrativo para sua comercialização.

Palavras-chave: Filme biodegradável. Feijão macáçar. Amido. Quitosana.

Abstract: The present research was conducted to extract starch from macáçar bean, chitosan from shrimp shells and evaluate the characteristics of the produced blends by different combinations of these raw materials. To obtain the films we used starch from macáçar bean $(3 \mathrm{~g} / 100 \mathrm{~g}$ of film-forming solution) and different percentages of chitosan and glycerol (0/20, 0/30,5/20,5/30,10/20 e 10/30), based-amount of starch $(\mathrm{m} / \mathrm{m})$, respectively. Solutions were spilled in Petri's glass-plates $(10 \mathrm{~mL})$ and dried at $40^{\circ} \mathrm{C}$, by $24 \mathrm{~h}$. The polymeric matrix, macáçar bean starch-chitosan-glycerol, presented excellent intermolecular interaction to obtain films with good uniformity, continuity, handling and transparency $(74,1562 \pm$ $4,8330 \%)$. The films obtained are suitable for transparent packaging of dehydrated products and with low moisture content, which require more attractive for commercialization.

Palavras-chave: Biodegradable film. Macáçar bean. Starch. Chitosan.

\section{INTRODUÇÃO}

A obtenção de filmes plásticos biodegradáveis tem despertado bastante inte-

\footnotetext{
${ }^{1}$ Instituto Federal de Educação, Ciência e Tecnologia do Rio Grande do Norte (IFRN), Nova Cruz, RN. E-mails: (djeson.mateus@ifrn.edu.br, leh06araujo@gmail.com, mayrathatiana@hotmail.com)
} 
resse pela comunidade científica mundial como forma de substituir o uso do plástico derivado de petróleo, tendo em vista que na sua produção utiliza-se matéria-prima de fonte renovável. Muitos trabalhos têm relatado o uso de amido na elaboração destes filmes, averiguando principalmente as adequações e limitações impostas por esse polímero natural na síntese destes materiais.

Devido a sua natureza hidrofílica, os filmes produzidos com amido são permeáveis ao vapor de água, apresentam baixa resistência mecânica, ao mesmo tempo em que apresentam baixa permeabilidade a gases, como $\mathrm{CO}_{2} \mathrm{e} \mathrm{O}_{2}$, sendo esta última uma característica desejada para alguns filmes plásticos (GHANBARZADEH; ALMASI; ENTEZAMI, 2010). Algumas dessas propriedades podem ser reparadas com a incorporação de aditivos a esses polímeros, como fibras naturais de origem vegetal (MÜLLER; LAURINDO; YAMASHITA, 2009; SCHEIBE, 2012) e de outras origens (RICARDO et al., 2009; FRÁGUAS et al., 2015; MELO; AOUADA; MOURA, 2017).

Experimentos realizados por diversos pesquisadores têm comprovado grande compatibilidade entre a matriz polimérica de amido e algumas fibras, em decorrência de interações intermoleculares entre os constituintes, resultando em filmes com meIhores propriedades mecânicas e de barreira (MORAES, 2013). Segundo Scheibe (2012), a adição de fibras de sisal melhora a estabilidade dos filmes, produzidos por tape-casting, pois reduzem seu caráter hidrofílico e o tornam mais resistente aos esforços mecânicos, muito embora reduzam a sua elasticidade. Melo, Aouada e Moura (2017) verificaram que o aumento na concentração de nano-partículas de quitosana reduziu significativamente 0 valor da permeabilidade ao vapor de água, de 2,470 \pm 0,101 para $1,904 \pm 0,125 \mathrm{~g} \mathrm{~mm} / \mathrm{kPa} \mathrm{h} \mathrm{m}^{2}$, em filmes à base de pectina (3\%). Com isso, as presenças dessas nano-partículas conferiram boa adequação nas propriedades dos filmes para aplicação em embalagens de alimentos.

A quitosana é um copolímero natural, que pode ser derivado da quitina, sendo a quitina um dos principais constituintes dos exoesqueletos dos animais marinhos (camarão, siri, caranguejo, ostras etc.) juntamente com $\mathrm{CaCO}_{3}$, proteínas, lipídeos e pigmentos (EINDU et al., 2004). Com base na produção anual de 2015, que foi de 69,9 mil toneladas de camarão (RN NOTíCIAS, 2015), o Brasil é um grande gerador de resíduos decorrentes das atividades da carcinocultura. Essa matéria-prima é descartada no meio ambiente, desperdiçando uma boa fonte de matéria-prima para obtenção de quitosana e, consequentemente, de geração de riquezas à sua população. 
Várias fontes de amido vêm sendo utilizadas para suprimento da demanda por esse polissacarídeo, como arroz, milho, mandioca, batata etc. Outra fonte de amido ainda pouco explorada com essa finalidade é o feijão, cuja estimativa de produção no Brasil, em 2018, é de 3,4 milhões de toneladas (IBGE, 2018). Segundo Salgado et al. (2005), o feijão macáçar (Vigna unguiculata (L.) Wap) ou caupi apresenta 19,92\% e $41,36 \%$ de amido nas fases verde e madura, respectivamente. Em ambas as fases ocorre predominância da quantidade de amilopectina (13,33\% e 27,10\%) em relação à de amilose $(5,51 \%$ e $15,63 \%)$.

Com essas características, o feijão macáçar pode ser uma fonte alternativa para obtenção de amido e, consequentemente, com ele pode-se produzir plásticos biodegradáveis, aplicação que poderá agregar mais valor econômico a essa cultura agrícola. Pesquisas desenvolvidas por Costa et al. (2017) proporcionaram a obtenção de filmes biodegradáveis com boa transparência, em torno de 80,95\% em relação àquela apresentada pelos filmes tradicionais, tendo como matriz polimérica amido de feijão macáçar, ácido acético glacial e glicerina.

Neste contexto, o aproveitamento dessas fontes de matérias-primas para elaboração de blendas biodegradáveis de amido de feijão macáçar-quitosana-glicerol apresenta-se como uma alternativa promissora em substituição às derivadas do petróleo.

\section{MATERIAL E MÉTODOS}

\subsection{Matérias-primas}

A matéria-prima utilizada como fonte de quitosana, exoesqueletos de camarão (Litopenaeus vanname, Aristeus antennatus), foi fornecida pelo proprietário do "Restaurante do Jubemal", no Município de Nova Cruz - RN, durante o mês de maio de 2017. Já o feijão macáçar (Vigna unguiculata), fonte de amido para elaboração das blendas, foi adquirido na feira livre do Município de Espírito Santo - RN, durante o mês de junho do mesmo ano. O camarão foi produzido pelos carcinicultores do município de Baia Formosa-RN e o feijão pelos agricultores do próprio município de Espírito Santo-RN. 
Todos os reagentes utilizados no processo de extração da quitosana, do amido e na elaboração das blendas são de grau analítico, ambos fornecidos pelo IFRN Campus Nova Cruz (Tabela 1).

Tabela 1 - Relação dos reagentes utilizados no trabalho

\begin{tabular}{lcc}
\hline \multicolumn{1}{c}{ Reagentes } & Simbologia & Marca \\
\hline Hidróxido de sódio em microesferas (P.A.) & $\mathrm{NaOH}$ & DINÂMICA \\
Ácido clorídrico (P.A.) & $\mathrm{HCl}$ & VETEC \\
Hipoclorito de sódio (P.A.) & $\mathrm{NaClO}$ & DINÂMICA \\
Ácido acético glacial (P.A.) & $\mathrm{CH}_{3} \mathrm{COOH}$ & VETEC \\
Glicerol (P.A.) & $\mathrm{C}_{3} \mathrm{H}_{8} \mathrm{O}_{3}$ & NEON \\
\hline
\end{tabular}

Fonte: Autor

\subsection{Extração da quitosana}

Inicialmente, lavaram-se as cascas de camarão em água corrente para retirar ovas, restos vegetais, terra, etc. Em seguida, procedeu-se uma nova lavagem com água destilada e colocaram-se as cascas para secar em estufa com circulação de ar, a $40{ }^{\circ} \mathrm{C}$, durante $24 \mathrm{~h}$. Após secagem, o material foi triturado em moinho de facas (SOLAB Multi uso - SL 35) e tamisado para homogeneização da granulometria (< 425 $\mu \mathrm{m})$. As etapas envolvidas no processamento das cascas de camarão para obtenção de quitosana estão indicadas na Figura 1.

Figura 1 - Etapas do processamento das cascas de camarão para obtenção de quitosana

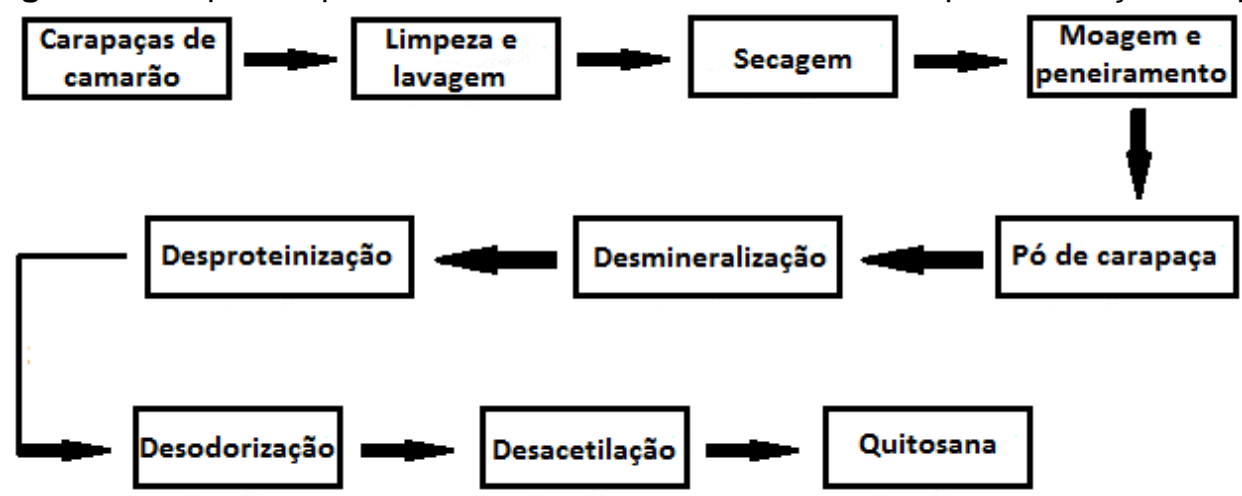

Fonte: Autor 
A desmineralização do pó foi realizada com ácido clorídrico ( $\mathrm{HCl})$ a 2,5\% (v/v), na proporção de 1:6, sob agitação, durante 1 hora, tendo como objetivo eliminar os carbonatos, fosfatos e diminuir o teor de cinzas. Para a redução do teor de nitrogênio realizou-se a desproteinização com solução de hidróxido de sódio (NaOH) a 5,0\% $(\mathrm{m} / \mathrm{v})$, na proporção de 1:6, sob agitação, durante 1 hora.

$\mathrm{Na}$ etapa de desodorização e remoção da pigmentação, a matéria-prima desproteinizada foi adicionada a uma solução de hipoclorito de sódio ( $\mathrm{NaClO})$ a 1\% (v/v), na razão de 1:3, permanecendo sob agitação durante 1 hora. Ao final desta etapa obteve-se a quitina, a qual foi submetida à desacetilação com uma solução de $\mathrm{NaOH}$ a 43\%, na proporção de 1:6, durante 2 horas, para a obtenção da quitosana.

Ao final de cada etapa o material obtido foi filtrado e lavado com água destilada até atingir $\mathrm{pH} \approx 7,0 \mathrm{e}$, em seguida, seco em estufa com circulação de ar, a $40{ }^{\circ} \mathrm{C}$, durante 24 h. Após a última etapa, o material obtido - quitosana - foi estocado em um freezer a $5^{\circ} \mathrm{C}$ para posterior utilização na elaboração das blendas.

\subsection{Extração do amido}

Os grãos de feijão macáçar, maduros e secos, foram selecionados, sendo descartados aqueles que apresentavam aspectos visuais com possíveis estados de decomposição, degradação química e/ou biológica. Após essa operação (catação), obteve-se uma massa de $900 \mathrm{~g}$ de matéria-prima. Em seguida, os grãos foram lavados em água corrente para remoção de sujeiras e particulados indesejáveis.

Para extração do amido, os grãos de feijão, selecionados e lavados, foram colocados em um liquidificador e, em seguida, se adicionou água, na razão de $200 \mathrm{~g}$ de grãos/L de água deionizada. A mistura foi triturada no liquidificador (Mondeal), sob baixa rotação, por um período de 10 minutos. Esse procedimento foi repetido até que toda massa de grãos selecionada fosse processada.

Após o processamento de toda matéria-prima, agitou-se a mistura e em seguida filtrou-se em peneira de 850 um (20 mesh), transferindo-se o conteúdo para um Becker plástico de 4000 mL. Essa operação foi repetida por duas vezes. Deixou-se o filtrado em repouso durante $24 \mathrm{~h}$ para que ocorresse a decantação do amido. O restante do material, constituído basicamente de fibras e retido na peneira, foi descartado. 
Decorridas as $24 \mathrm{~h}$ de decantação do conteúdo amiláceo - constituído basicamente de amilose e amilopectina - separou-se a parte decantada, da sobrenadante, por meio de uma centrífuga (FANEM Excelsa II, mod. 206 BL), a 3600 rpm, por um período de 10 minutos. Em seguida, colocou-se a massa sólida, rica em amido, para desidratação em estufa a $60{ }^{\circ} \mathrm{C}$, durante $24 \mathrm{~h}$. Depois triturou-se o material seco em um moinho de faca (SOLAB Multi uso - SL 35) e procedeu-se a homogeneização dos grânulos de amido em peneira de $425 \mu \mathrm{m}$ (40 mesh), os quais foram utilizados no preparo das soluções filmogênicas.

\subsection{Preparo das soluções filmogênicas}

Os filmes foram preparados nos Laboratórios de Química Analítica e Química Instrumental do Instituto Federal de Educação, Ciência e Tecnologia do Rio Grande do Norte - Campus Nova Cruz, seguindo a técnica de evaporação do solvente, mais conhecida como casting, com algumas adaptações. As soluções filmogênicas foram preparadas misturando-se amido (AM), glicerol (GL) e quitosana (QT), adotando-se as combinações apresentadas na Tabela 2. Cada combinação foi identificada por quatro dígitos separados por underline $\left(\_\right.$) na forma: AM_GL_QT, em que AM significa a porcentagem de amido, GL a porcentagem de glicerol e QT a porcentagem de quitosana.

Tabela 2 - Combinações adotadas para as formulações das soluções filmogênicas

\begin{tabular}{cccc}
\hline Formulações & $\begin{array}{c}\text { AM (g/100 g de } \\
\text { solução) }\end{array}$ & $\begin{array}{c}\text { GL (g/100 g de } \\
\text { AM) }\end{array}$ & $\begin{array}{c}\text { QT (g/1000 g de } \\
\text { AM) }\end{array}$ \\
\hline AM03_GL20_QT00 & 3 & 20 & 0 \\
AM03_GL20_QT05 & 3 & 20 & 5 \\
AM03_GL20_QT10 & 3 & 20 & 10 \\
AM03_GL30_QT00 & 3 & 30 & 0 \\
AM03_GL30_QT05 & 3 & 30 & 5 \\
AM03_GL30_QT10 & 3 & 30 & 10 \\
\hline
\end{tabular}

Fonte: Autor

As soluções filmogênicas, após preparadas, foram agitadas e aquecidas em Banho Maria (Quimis), a uma taxa de $1,75^{\circ} \mathrm{C} / \mathrm{min}$., até atingir a temperatura de $95^{\circ} \mathrm{C}$, permanecendo nesta temperatura por aproximadamente 10 minutos e, em seguida, aplicadas sobre placas de petri $(\varnothing=9 \mathrm{~cm})$. Colocou-se para a formação do filme, em 
média, $0,23 \mathrm{~g} / \mathrm{cm}^{2}$ ( $\approx 10 \mathrm{~mL}$ ) da solução filmogênica em cada placa de Petri. As soluções foram postas para desidratação em estufa com ventilação forçada, a $40^{\circ} \mathrm{C}$, por $24 \mathrm{~h}$ e, logo após, acondicionadas em ambiente com atmosfera saturada em $\mathrm{NaCl}$, à temperatura de aproximadamente $25^{\circ} \mathrm{C}$, por um período de 5 dias, para posterior retirada dos filmes (YANG; PAULSON, 2000).

\subsection{Caracterização dos filmes}

Neste capítulo serão descritas as análises sensoriais: continuidade, manuseabilidade e uniformidade (ausência de partículas insolúveis, bolhas de ar ou zonas de opacidade); e as análises físico-químicas: umidade, espessura, densidade, gramatura, transparência, permeabilidade ao vapor d'água e solubilidade em água dos filmes produzidos à base de amido de feijão macáçar, glicerol e quitosana.

\subsubsection{Continuidade}

Verificou-se visualmente a ausência, ou não, de ruptura após a secagem do filme. Utilizou-se como critério o "SIM" para o filme em estado aceitável e o "NÃO" para o filme em condições inaceitáveis.

\subsubsection{Manuseabilidade}

Analisou-se a facilidade de manuseio sem o risco de ruptura, se o material era duro e se tinha facilidade de rasgar. Como critério de aceitabilidade adotou-se também o "SIM" e o "NÃO" para o aceitável e inaceitável, respectivamente.

\subsubsection{Uniformidade}

Examinou-se na superfície do filme a ausência, ou não, de partículas insolúveis, bolhas de ar ou zonas de opacidade, empregando-se os mesmos critérios que os utilizados nas análises da continuidade e manuseabilidade ("SIM" e "NÃO"), conforme a aceitação. 
Devido a inexistência de equipamentos adequados, não foi possível fazer a determinação da tensão de ruptura, Módulo de Yang e a análise microscópica da superfície dos filmes.

\subsubsection{Umidade}

Determinou-se a umidade coletando-se 3 (três) amostras de filme, medindo cada uma aproximadamente $63,585 \mathrm{~cm}^{2}$ (área da placa de Petri), tendo sido previamente medidas suas respectivas massas em balança analítica (BIOSCALE), e, em seguida, colocadas em estufa (LUCADEMA) a $105^{\circ} \mathrm{C}$ por 24 horas. O cálculo da umidade foi realizado utilizando-se a Equação 1:

$U=\frac{\left(m_{i}-m_{f}\right)}{m_{i}} .100$

onde, $U$ é a porcentagem de umidade, $m_{i}$ é a massa inicial e $m_{f}$ a massa final do filme após secagem.

\subsubsection{Solubilidade do biofilme em água}

Para essa determinação, seguiu-se o método proposto por Gontard et al. (1994), com algumas adaptações. Colocou-se uma amostra de filme, com aproximadamente $63,585 \mathrm{~cm}^{2}$, em estufa (LUCADEMA) a $105^{\circ} \mathrm{C}$ por 24 horas, em seguida, a amostra foi pesada $\left(m_{i}\right)$ numa balança analítica (BIOSCALE) e inserida em um Erlenmeyer contendo aproximadamente $100 \mathrm{~mL}$ de água destilada, sob agitação em shaker (IKA C MAG - HS 7), a $25^{\circ} \mathrm{C}$ por 24 horas. Após esse período, descartou-se a porção líquida, e o filme foi novamente colocado na estufa a $105^{\circ} \mathrm{C}$ por 24 horas, para secagem e posterior medida de sua massa final $\left(m_{f}\right)$. Com esse procedimento, realizado em triplicata, determinou-se a perda de massa $\left(p_{m}\right)$ por solubilização do filme (Equação 2).

$$
p_{m}=\frac{\left(m_{i}-m_{f}\right)}{m_{i}} .100
$$




\subsubsection{Gramatura}

O cálculo da gramatura foi realizado utilizando-se a razão entre a massa do filme dividida pela respectiva área ocupada, sendo o resultado expresso em $\mathrm{g} / \mathrm{cm}^{2}$. Para isso fez-se uso da Equação 3:

$$
G=\frac{m_{s}}{A}
$$

onde, $G$ é a gramatura expressa em $\mathrm{g} / \mathrm{cm}^{2}, m_{s}$, é a massa do filme e $A$ é a área ocupada pelo filme.

\subsubsection{Espessura}

A medida da espessura dos filmes foi feita com micrômetro digital (TMX MED25) com resolução de 0,001 mm, em 10 posições aleatórias para cada amostra. Neste caso, a espessura do filme foi considerada como sendo a média das dez leituras (SOBRAL, 1999).

\subsubsection{Densidade}

A densidade foi determinada cortando-se amostras dos filmes com dimensões de $2 \mathrm{~cm} \times 2 \mathrm{~cm}$. Essas amostras foram desidratadas em dessecador contendo sílica gel por três semanas e depois pesadas (MÜLLER; LAURINDO; YAMASHITA, 2009). O cálculo desse parâmetro $\left(\mathrm{g} / \mathrm{cm}^{3}\right)$ foi feito utilizando a equação 4 :

$$
D=\frac{m}{A \cdot e}
$$

onde, $m$ é a massa (g) da amostra do biofilme, $A$ e e são a área $\left(\mathrm{cm}^{2}\right)$ e a espessura (cm) da amostra do filme, respectivamente.

\subsubsection{Transparência}

A caracterização da transparência foi feita no Laboratório de Instrumentação Analítica do IFRN - Campus Nova Cruz, utilizando um espectrofotômetro UV.- VIS, 
marca Thermo Scientific, modelo Evolution 60S - UV Visible Spectrophotometer, sendo avaliada indiretamente pela transmitância, na faixa de comprimento de onda de $720 \mathrm{~nm}$. O teste em branco foi realizado com água destilada.

\subsubsection{Permeabilidade ao vapor de água}

Amostras de filme com aproximadamente $5 \mathrm{~cm}$ de diâmetro foram fixadas em um Erlenmeyer de $125 \mathrm{~mL}$, contendo $100 \mathrm{~mL}$ de água destilada, vedadas as extremidades com fita adesiva, garantindo assim que todo vapor de água que migrasse ocorresse através do filme. Mediu-se a massa inicial do sistema (Erlenmeyer + água + filme + acessórios) e acondicionou-se em dessecador, a $25^{\circ} \mathrm{C}$, em seguida realizaramse pesagens a cada $2 \mathrm{~h}$, por um intervalo de 24 horas.

Os dados obtidos foram expressos pela quantidade de massa permeada $(m)$ em função da área $(A)$ e do tempo de ensaio $(t)$. O fluxo de vapor d'água $(J)$ foi calculado pela equação 5 .

$J=\frac{\Delta m}{A . t}$

onde $\Delta m$ é a variação de massa (g) e $A$ é a área da abertura do Erlenmeyer $\left(\mathrm{cm}^{2}\right)$, equivalente a área de exposição à percolação do vapor de água através do filme $\left(1,886 \mathrm{~cm}^{2}\right)$ e t é o tempo em dia.

\subsection{Análise estatística}

Para análise estatística dos resultados foi empregado o programa computacional Assistat - Versão 7.7. Foram realizadas análises de variância (ANOVA) e teste de Tukey para comparação das médias, com nível de significância de $5 \%(P \leq 0,05)$.

\section{RESULTADOS E DISCUSSÃO}

Nesta etapa serão abordados os resultados obtidos no desenvolvimento deste trabalho, referentes à extração do amido de feijão macáçar, da extração da quitosana e dos procedimentos para obtenção das blendas e sua respectiva caracterização. 


\subsection{Extração do amido de feijão macáçar}

Através do processo utilizado para a extração do amido de feijão macáçar, obteve-se um produto com baixo teor de umidade e de cinzas, cujos valores foram $10,4382 \pm 0,0623 \%$ e 0,6124 \pm 0,0363\% respectivamente. Com respeito a essas determinações, o produto obtido se encontra parcialmente em condições de ser comercializado no mercado brasileiro, cuja Legislação admite um índice máximo de 14\% de umidade e de $0,5 \%$ de cinzas, para amidos comerciais comestíveis (ANVS, 1978). Embora o índice de cinzas tenha sido ligeiramente superior ao permitido na Legislação, o mesmo está bastante inferior aos resultados obtidos para o amido de milho e de fécula de batata por Lima et al. (2012), os quais foram iguais a 0,96 $\pm 0,09 \%$ e 0,87 $\pm 0,23 \%$, respectivamente.

\subsection{Extração de quitosana}

Apesar de não ter sido feita a caracterização da quitosana, admite-se que o procedimento utilizado e o produto obtido foram adequados e coerentes com a finalidade da pesquisa tendo em vista que a utilização dessa matéria-prima proporcionou melhor qualidade aos filmes produzidos.

\subsection{Caracterização dos filmes}

Os filmes produzidos à base de amido de feijão macáçar plastificados com glicerol e reforçados com quitosana apresentaram boa continuidade, uniformidade e fácil manuseabilidade. Não foi observada a formação de bolhas, rachaduras e presença de material insolúvel na sua superfície, o que vem a corroborar os resultados obtidos por Araújo (2014), ao trabalhar com filmes biodegradáveis de amido, incorporado com extrato de própolis. No entanto, quando secos em estufa a $105^{\circ} \mathrm{C}$, durante 24 horas, os filmes tornaram-se amarelados e quebradiços (Figura 2), fato também observado por Costa et al. (2017). 
Figura 2 - Aspectos visuais dos filmes antes (A) e depois (B) de secos em estufa, a $05^{\circ} \mathrm{C}$, por $24 \mathrm{~h}$

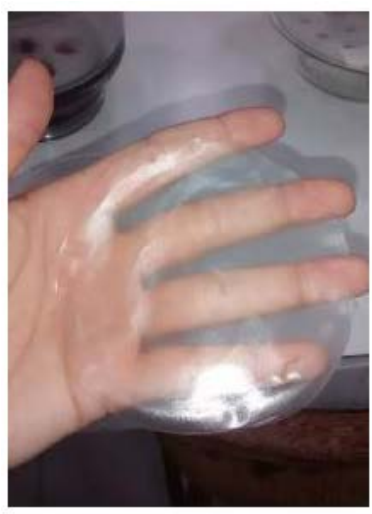

(A)

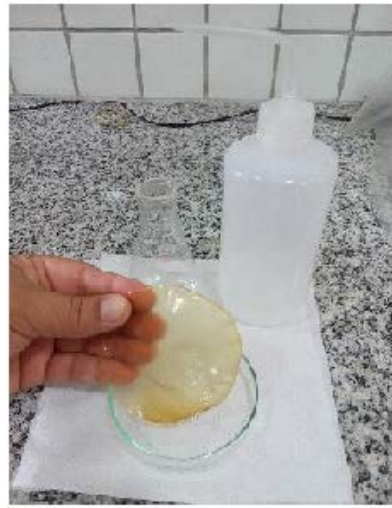

(B)

Fonte: Autor

Transcorridos 5 (cinco) dias após a secagem e exposto ao meio ambiente (a $25^{\circ} \mathrm{C}$ ), os filmes adquiriram novamente plasticidade, comprovando seu carácter hidrofílico (SOBRAL, 2000; MALI et al., 2005).

\subsubsection{Espessura e gramatura}

As análises dos dados obtidos para a espessura e gramatura dos filmes produzidos à base de amido de feijão macáçar, plastificado e reforçados com diferentes concentrações de glicerol e quitosana, respectivamente, encontram-se representadas na Figura 3.

Figura 3 - Variação da espessura (A) e da gramatura (B) dos filmes em função da quantidade de glicerol e quitosana

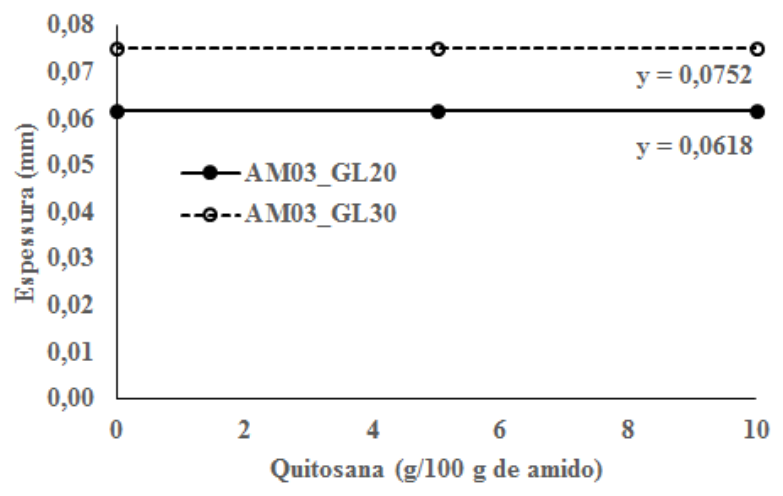

(A)

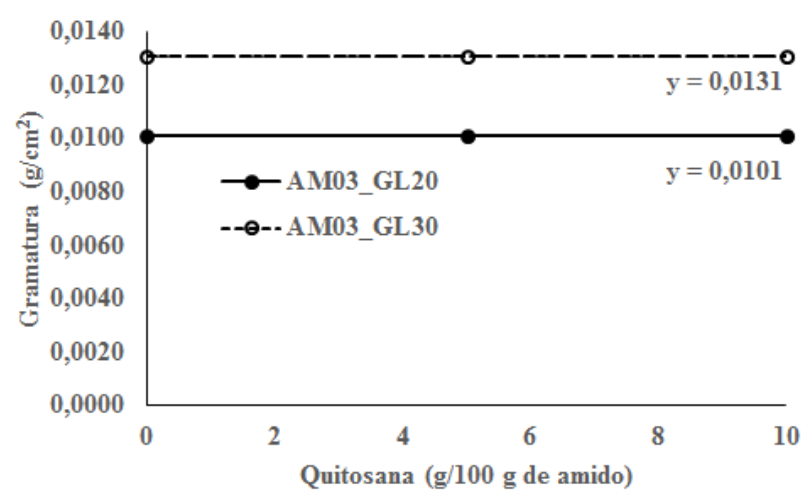

(B)

Fonte: Autor 
Observa-se que o aumento na quantidade de glicerol produziu filmes mais espessos, o que pode ser justificado pelo próprio aumento de massa desse constituinte na blenda e, também, do seu carácter hidrofílico (MÜLLER, 2007), ocasionando maior retenção de umidade durante o processo de secagem, que incorpora maior quantidade de material ao filme. Isto pode ser evidenciado pela proximidade entre as relações das massas de glicerol nas blendas com GL30 e GL20, que foi de 1,5 e das respectivas espessuras, que foi de 1,22. Por outro lado, a espessura e gramatura, não variaram com o acréscimo da quantidade de quitosana utilizada como aditivo reforçador dos filmes. Isto ocorre devido ao fato das partículas de quitosana interagirem fortemente com a matriz polimérica amido-glicerol, proporcionando uniformidade às referidas propriedades dos filmes (SCHEIBE, 2012).

Contudo, a formulação que utilizou maior quantidade de glicerol e quitosana (AM3_GL30_GT10) manteve espessura de filmes $(0,0796 \pm 0,0083 \mathrm{~mm})$ inferiores aos obtidos por Shimazu, Mali e Grossmann (2007) e Costa et al. (2017), indicando que o método empregado foi adequado.

Analogamente, o valor para a gramatura variou de 0,0086 $\pm 0,0016 \mathrm{~g} / \mathrm{cm}^{2}$, na formulação com menor quantidade de plastificante e de reforçador (AM3_GL20_QT00), para 0,0143 $\pm 0,0017 \mathrm{~g} / \mathrm{cm}^{2}$, na formulação com maior quantidade de aditivos (AM3_GL30_QT10).

\subsubsection{Umidade e densidade}

Os tratamentos aplicados na elaboração dos filmes não afetaram o teor de umidade dos mesmos ( $P \leq 0,05$ ), cujo valor médio foi igual a 13,4522 $\pm 2,8025 \%$ (Tabela 3). Este fato contraria as observações feitas por Isotton (2013) e Costa et al. (2017), os quais observaram aumento no teor de umidade com o acréscimo da concentração de glicerol, em filmes de amido. Segundo Lourdin et al. (1997), isso pode ser ocasionado pelo efeito antiplastificante, devido às fortes interações entre o plastificante, o amido e a quitosana (ligações de hidrogênio), que reduz a mobilidade molecular e a capacidade de ligação com a água. O teor de umidade encontrado foi inferior ao observado por Santos et al. (2013) e Costa et al. (2017), em filme de amido-glicerol. 
Tabela 3 - Valores médios obtidos para a densidade $\left(\mathrm{g} / \mathrm{cm}^{3}\right)$ e a umidade $(\%)$ dos filmes

\begin{tabular}{lccc}
\hline & \multicolumn{3}{c}{ Densidade } \\
\hline Formulações & QT00 & QT05 & QT10 \\
AM03_GL20 & $1,4430^{\text {aA }}$ & 1,6931 aA & $1,7213^{\text {aA }}$ \\
AM03_GL30 & $1,7021^{\text {aA }}$ & $1,7200^{\text {aA }}$ & $1,7990^{\text {aA }}$ \\
\hline \multicolumn{4}{c}{ Umidade } \\
\hline Formulações & QT00 & QT05 & QT10 \\
AM03_GL20 & 15,8406 aA & $12,9953^{\text {aA }}$ & $12,8965^{\text {aA }}$ \\
AM03_GL30 & $12,7287^{\text {aA }}$ & $10,7033^{\text {aA }}$ & $15,5488^{\text {aA }}$ \\
\hline
\end{tabular}

As médias seguidas pela mesma letra minúscula nas colunas e mesma letra maiúscula nas linhas não diferem estatisticamente entre si. Foi aplicado o Teste de Tukey ao nível de $5 \%$ de probabilidade $(P \leq 0,05)$.

Fonte: Autor

A técnica utilizada para a obtenção dos filmes de amido de feijão macáçar, plastificado com glicerol e reforçado com quitosana, nas diferentes formulações experimentadas, proporcionou um controle satisfatório da densidade dos filmes, visto que ambos apresentaram estatisticamente a mesma magnitude $(P \leq 0,05)$. $O$ valor médio para a densidade dos filmes foi igual a 1,6797 $\pm 0,2402 \mathrm{~g} / \mathrm{cm}^{3}$ (Tabela 3), valor superior ao obtido por Costa et al. (2017), ao trabalhar com filmes de amido de feijão macáçar e glicerol. O elevado valor desse parâmetro, em relação ao observado por outros autores, pode estar relacionado à adição da quitosana à solução filmogênica, que durante o processo de secagem dos filmes não sofre perda, conferindo maior massa aos mesmos.

\subsubsection{Transparência e solubilidade em água}

A transparência dos filmes, propriedade oposta à opacidade, foi medida por meio da transmitância de luz (\%) e seus valores indicaram que os tratamentos não afetaram essa propriedade dos filmes $(P \leq 0,05)$, cujo valor médio foi $74,1562 \pm$ 4,8330\% (Tabela 4). Esse efeito indica que as dosagens de aditivo reforçador - quitosana - foram efetivamente incorporadas à matriz polimérica amido-glicerol, não afetando, consequentemente, a transparência dos filmes produzidos. Observações semelhantes foram feitas por Henrique (2002) ao produzir filmes de fécula de mandioca modificada. Costa et al. (2017) verificaram transparência equivalente ao trabalharem com filmes de amido-glicerol. Por apresentar boa transparência, os filmes produzidos à base de amido de feijão macáçar-glicerol-quitosana, nas proporções testadas, são 
adequados para embalagem de alimentos desidratados ou com baixo teor de umidade, os quais requerem um maior atrativo para a sua comercialização.

Tabela 4 - Valores da transparência (\%) e solubilidade dos filmes ( $\mathrm{g} / 100 \mathrm{~mL}$ de água) à base de amido de feijão macáçar, plastificado com glicerol e reforçados com quitosana

\begin{tabular}{lccc}
\hline & \multicolumn{3}{c}{ Transparência } \\
\hline Formulações & QT00 & QT05 & QT10 \\
AM03_GL20 & $77,6740^{\mathrm{aA}}$ & $71,3050^{\mathrm{aA}}$ & $73,5737^{\mathrm{aA}}$ \\
AM03_GL30 & $78,5507^{\mathrm{aB}}$ & $73,9477^{\mathrm{aB}}$ & $69,8860^{\mathrm{aB}}$ \\
\hline \multicolumn{4}{c}{ Solubilidade } \\
\hline Formulações & QT00 & QT05 & QT10 \\
AM03_GL20 & $14,7450^{\mathrm{aA}}$ & $13,4127^{\mathrm{aA}}$ & $15,7527^{\mathrm{aA}}$ \\
AM03_GL30 & $10,4027^{\mathrm{bB}}$ & $11,4277^{\mathrm{bB}}$ & $11,9777^{\mathrm{bB}}$ \\
\hline
\end{tabular}

As médias seguidas pela mesma letra minúscula nas colunas e mesma letra maiúscula nas linhas não diferem estatisticamente entre si. Foi aplicado o Teste de Tukey ao nível de $5 \%$ de probabilidade $(P \leq 0,05)$.

Fonte: Autor

A solubilidade encontrada para os filmes biodegradáveis à base de amido de feijão macáçar-glicerol-quitosana foi significativamente modificada com o aumento da concentração de plastificante, mas não se alterou com a variação do agente reforçador ( $P \leq 0,05)$. Seu valor médio variou de 14,6368 $\pm 1,9748 \%$, com $20 \%$ de glicerol, para 11,2393 \pm 0,9188\%, com 30\% de glicerol, indicando redução no valor desse parâmetro com o aumento da quantidade de plastificante. Segundo Rocha et al. (2014), a redução na solubilidade, em alta concentração de glicerol, pode estar associada ao aumento da interação glicerol-quitosana e/ou carboidrato, deixando menos sítios ativos para a interação com a água.

Constatou-se baixa solubilidade dos filmes obtidos com ambas as formulações, a qual foi inferior à solubilidade dos filmes de amido de pinhão produzidos pela técnica de casting, por Silva (2011), que foi 18,7 \pm 0,4\% e, equivalente à dos filmes de amido de mandioca e proteína de soja, por Rocha et al. (2014), que foi $14,8 \%$.

Com essa característica de baixa solubilidade, os filmes produzidos podem ser utilizados em produtos que necessitem de embalagens com menor solubilidade. Seu uso é inadequado para alimentos que entram em contato com a água e precisam ser solubilizados, mas podem atuar como proteção para alimentos em que a atividade de água é alta, quando o alimento entra em contato com a água durante a cocção ou mesmo quando os filmes são ingeridos (comestíveis), conforme Silva (2011). 


\subsubsection{Permeabilidade ao vapor de água}

Observa-se que a quantidade de vapor d'água percolada através dos filmes (Figura 4), nas primeiras $24 \mathrm{~h}$ de ensaio, foi efetivamente modificada em função das mudanças nas formulações das soluções filmogênicas, tanto em relação à quantidade de glicerol quanto de quitosana $(P \leq 0,05)$.

Figura 4 - Análise estatística para a quantidade de vapor de água percolado através dos filmes, durante o período de $24 \mathrm{~h}$

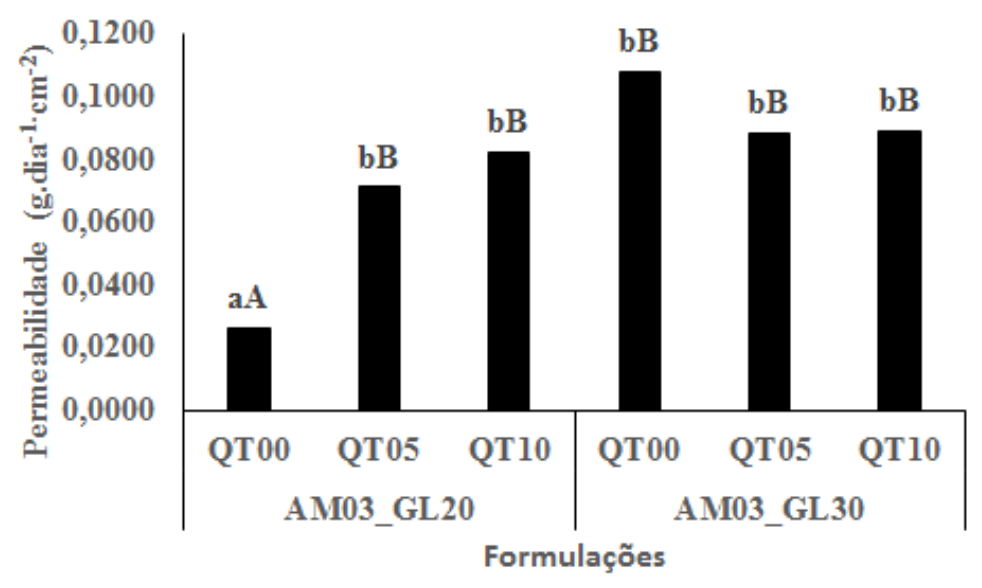

Fonte: Autor

Verifica-se, portanto, que os filmes produzidos a partir da formulação que apresentava maior concentração de glicerol e quitosana (AM03_GL30_QT10) tornaram-se mais permeáveis ao vapor de água, quando comparados à formulação com menor quantidade desses aditivos (AM03_GL20_QTO0). Contudo, constata-se uma elevação da taxa de percolação com o aumento do teor de quitosana nos filmes elaborados com menor quantidade de plastificante (GL20). Esse efeito não foi significativo ( $P \leq$ $0,05)$ nos filmes com maior quantidade de glicerina (GL30). Esse comportamento pode ser justificado devido ao aumento do carácter hidrofílico dos polímeros, o que pode limitar a sua aplicação na forma de embalagem (CARVALHO; GROSSO, 2006). valor mínimo observado de 0,0262 $\pm 0,0017 \mathrm{~g} \cdot \mathrm{dia}^{-1} \cdot \mathrm{cm}^{-2}$ encontra-se ligeiramente superior ao obtido por Fráguas et al. (2015), ao produzirem filmes à base de quitosana, cujo valor médio foi de $0,0170 \mathrm{~g} \cdot \mathrm{dia}^{-1} \cdot \mathrm{cm}^{-2}$. 


\section{CONCLUSÕES}

O amido de feijão macáçar e a quitosana dos exoesqueletos de camarão apresentaram efetiva interação entre si pois, com eles, obtiveram-se biofilmes com características compatíveis com aqueles obtidos por outros pesquisadores, além de proporcionarem a formação de filmes com melhores características que aqueles sem a quitosana.

Os aumentos das quantidades de glicerol e de quitosana proporcionaram a formação de filmes mais permeáveis ao vapor de água. Contudo, as dosagens de quitosana não afetaram a solubilidade dos mesmos.

Os filmes obtidos apresentaram espessuras e densidades bastantes uniformes, mesmo que empregando formulações diferentes entre seus constituintes.

Os filmes obtidos são adequados para embalagens transparentes de produtos desidratados e com baixo teor de umidade, os quais requerem maior atrativo para sua comercialização.

\section{AGRADECIMENTOS}

Agradecemos a gestão do Instituto Federal de Educação, Ciência e Tecnologia do Rio Grande do Norte - Campus Nova Cruz pelo apoio material e humano disponibilizados para a realização de nossa pesquisa.

\section{REFERÊNCIAS}

ANVISA - AGÊNCIA NACIONAL DE VIGILÂNCIA SANITÁRIA. Gerência-Geral Alimentos, Resolução - "CNNPA no 12, de 1978", Diário Oficial da República Federativa do Brasil, Brasília, 24 jul. 1978. Disponível em: <http:// www.anvisa.gov.br/legis/resol/12_78.pdf>. Acesso em: 24 jan. 2018.

ARAÚJO, G. K. P. Desenvolvimento de Filmes Biodegradáveis de Amido Incorporado com Extrato de Própolis. 2014. 43 f. Trabalho de Conclusão de Curso (Graduação em Tecnologia de Alimentos) - Universidade Tecnológica Federal do Paraná, Campo Mourão, 2014.

CARVALHO, R. A.; GROSSO, C. R. F. Efeito do tratamento térmico e enzimático nas propriedades de filmes de gelatina. Ciência e Tecnologia de Alimentos, Campinas, v. 26, n. 3, p. 495-501, jul./set. 2006. Disponível em: <http://dx.doi.org/10.1590/S0101-

20612006000300002>. Acesso em: 11 jan. 2018. 
COSTA, D. M. A.; SANTOS, A. F.; SILVA, E. D.; SILVA, I. A. Desenvolvimento e caracterização de filmes à base de amido de feijão macáçar (Vigna unguiculata (L.) Wap). Holos, Natal, ano 33, v. 7, p. 2-16, 2017. Disponível em: <https://doi.org/10.15628/holos.2017.6318>. Acesso em: 25 jan. 2018.

EINDU, A.; NAESS, S. N.; ELGSAETER, A.; VARUM, K. M. Solution Properties of Chitin in Alcali. Biomacromolecules, Trondheim, v. 5, n. 5, p. 2048-2054, Aug. 2004. Disponível em: <http://doi.org/10.1021/bm049710d >. Acesso em: 13 mar. 2018.

FRÁGUAS, R. M.; SIMÃO, A. A.; FARIAS, P. V.; QUEIROZ, E. R.; OLIVEIRA, E. N.; Jr., ABREU, C. M. P. Preparo e caracterização de filmes comestíveis de quitosana. Polímeros, São Carlos, v. 25, n. especial, p. 48-53, dez. 2015. Disponível em:

<http://dx.doi.org/10.1590/0104-1428.1656>. Acesso em: 12 abr. 2018.

GHANBARZADEH, B.; ALMASI, H.; ENTEZAMI, A. A. Physical properties of edible modified starche/carboxymethyl cellulose films. Innovative Food Science \& Emerging Technologies, Oxford, v. 11, n. 4, p. 697-702, Oct. 2010. Disponível em:

<https://doi.org/10.1016/j.ifset.2010.06.001>. Acesso em: 12 abr. 2018.

GONTARD, N.; DUCHEZ, C.; CUQ, J. L.; GUILBERT, S. Edible composite film of wheat gluten and lipids water vapor permeability and other physical properties. International Journal of Food Sciences and Technology, Oxford, v. 29, n. 1, p. 39-50, Feb. 1994. Disponível em: <https://doi.org/10.1111/j.1365-2621.1994.tb02045.x>. Acesso em: 14 abr. 2018.

HENRIQUE, C. M. Caracterização de filmes de féculas modificadas de mandioca como subsídios para aplicação em pós-colheita de hortícolas. 2002. 154 f. Tese (Doutorado em Agronomia/Horticultura) - Faculdade de Ciências Agronômicas, Universidade Estadual Paulista "Júlio Mesquita Filho", Botucatu, 2002.

IBGE - INSTITUTO BRASILEIRO DE GEOGRAFIA E ESTATÍSTICA. IBGE prevê safra de grãos 6,8\% menor em 2018. Disponível em: <https://agenciadenoticias.ibge.gov.br/agencianoticias/2013-agencia-de-noticias/releases/19474-ibge-preve-safra-de-graos-6-8-menor-em2018.html>. Acesso em: 18 abr. 2018.

ISOTTON, F. S. Desenvolvimento e caracterização de filmes de amido de milho eterificado com plastificante glicerol, sorbitol e poli (álcool vinílico). 2013. 100 f. Dissertação (Mestrado em Engenharia de Processos e Tecnologias), Universidade de Caxias do Sul, Caxias do Sul, 2013.

LIMA, B. N. B.; CABRAL, T. B.; NETO, R. P. C.; TAVARES, M. I. B. Estudo do Amido de Farinhas Comerciais Comestíveis. Polímeros, São Carlos, v. 22, n. 5, p. 486-490, out. 2012. Disponível em: <http://dx.doi.org/10.1590/S0104-14282012005000062>. Acesso em: 17 maio 2017.

LOURDIN, D.; COIGNARD, L.; BIZOT, H.; COLONNA, P. Influence of equilibrium relative humidity and plasticizer concentration on the water content and glass transition of starch materials. Polymer: The Chemistry, Physics and Technology of High Polymer, London, v. 38, n. 21, p. 5401-5406, Oct. 1997. Disponível em: <https://doi.org/10.1016/S00323861(97)00082-7>. Acesso em: 25 maio 2017.

MALI, S.; SAKANAKA, L. S.; YAMASHITA, F.; GROSSMANN, M. V. E. Water sorption and mechanical properties of cassava starch films and their relation to plasticizing effect. Carbohydrate Polymer, Londrina, v. 60, n. 3, p. 283-289, May, 2005. Disponível em: <https://doi.org/10.1016/j.carbpol.2005.01.003>. Acesso em: 21 out. 2016. 
MELO, P. T. S.; AOUADA, F. A.; MOURA, M. R. Fabricação de filmes bionanocompósitos à base de pectina e polpa de cacau com potencial uso como embalagem para alimentos. Química Nova, São Paulo, v. 40, n. 3, p. 247-251, 2017. Disponível em:

<http://dx.doi.org/10.21577/0100-4042.20160188>. Acesso em: 08 jul. 2017.

MORAES, J. O. Produção e caracterização de filmes de amido-glicerol-fibras de celulose elaborados por tape-casting. 2013. $176 \mathrm{f}$. Tese (Doutorado em Engenharia de Alimentos) - Centro Tecnológico, Universidade Federal de Santa Catarina, Florianópolis, 2013.

MÜLLER, C. M. O. Estudo dos processos de transferência de massa e propriedades mecânicas de biofilmes de amido de mandioca reforçados com fibras de celulose. 2007. 174 f. Tese (Doutorado em Ciência de Alimentos) - Centro de Ciências Agrárias, Universidade Estadual de Londrina, Londrina, 2007.

MÜLLER, C. M. O.; LAURINDO, J. B.; YAMASHITA, F. Effect of cellulose fibers addition on the mechanical properties and water vapor barrier of starch-based films. Food Hydrocolloids, Amsterdam, v. 23, n.5, p. 1328-1333, Jul. 2009. Disponível em:

<https://doi.org/10.1016/j.foodhyd.2008.09.002>. Acesso em: 10 abr. 2017.

RICARDO, N. M. P. S.; GOMES, A. M. M.; SILVA, P. L.; MOURA, C. L.; SOUZA, T. V. P. Estudo das propriedades mecânicas e biodegradáveis de blendas de amido de mandioca/quitosana/PVA. In: CONGRESSO BRASILEIRO DE POLÍMEROS, 10., 2009, Foz do Iguaçu. Anais... Foz de Iguaçu: Revista Polímeros, 2009. p. 1-8.

RN NOTÍCIAS. Estado - RN é segundo maior produtor de camarão em 2015. Disponível em: <http://mossorohoje.com.br/noticias/12099/8203rn-e-segundo-maior-produtor-de-camarao-em-2015>. Acesso em: 04 jan. 2018.

ROCHA, G. O.; FARIAS, M. G.; CARVALHO, C. W. P.; ASCHERI, J. L. R.; GALDEANO, M. C. Filmes compostos biodegradáveis a base de amido de mandioca e proteína de soja. Polímeros, São Carlos, v. 24, n. 5, p. 587-595, set. 2014. Disponível em:

<http://dx.doi.org/10.1590/0104-1428.1355>. Acesso em: 26 nov. 2017.

SALGADO, S. M.; GUERRA, N. B.; ANDRADE, S. A. C.; LIVERA, A. V. S. Caracterização físico-química do grânulo do amido do feijão caupi. Ciência e Tecnologia de Alimentos, Campinas, v. 25, n. 3, p. 525-530, jul./set. 2005. Disponível em:

<http://dx.doi.org/10.1590/S0101-20612005000300022>. Acesso em: 12 set. 2017.

SANTOS, B.; SILVA, R. S.; COELHO, T. M.; FILHO, N. A. Produção de bioplástico a partir do amido de mandioca. In: ENCONTRO INTERNACIONAL DE PRODUÇÃO CIENTÍFICA CESUMAR, 8.,2013, Maringá. Anais... Maringá: Ed. CESUMAR, 2013. p. 1-5.

SCHEIBE, A. S. Produção e caracterização de embalagem biodegradável de amido de mandioca e fibras utilizando a técnica de tape-casting. 2012. 131 f. Dissertação (Mestrado em Engenharia de Alimentos) - Centro Tecnológico, Universidade Federal de Santa Catarina, Florianópolis, 2012.

SHIMAZU, A. A.; MALI, S.; GROSSMANN, M. V. E. Efeitos plastificante e antiplastificante do glicerol e do sorbitol em filmes biodegradáveis de amido de mandioca. Semina: Ciências Agrárias, Londrina, v. 28, n. 1, p. 79-88, jan./mar. 2007. Disponível em:

<http://dx.doi.org/10.5433/1679-0359.2007v28n1p79>. Acesso em: 11 ago. 2017. 
SILVA, E. M. Produção e caracterização de filmes biodegradáveis de amido de pinhão. 2011. 43 f. Trabalho Conclusão de Curso (Bacharel em Engenharia Química) - Departamento de Engenharia Química, Universidade Federal do Rio Grande do Sul, Porto Alegre, 2011.

SOBRAL, P. J. A. Propriedades funcionais de biofilmes de gelatina em função da espessura. Ciência \& Engenharia, Uberlândia, v. 8, n. 1, p. 60-67, 1999.

SOBRAL, P. J. A. Influência da espessura de biofilmes feitos à base de proteínas miofibrilares sobre suas propriedades funcionais. Pesquisa Agropecuária Brasileira, Brasília (DF), v. 35, n. 6, p. 1251-1259, jun. 2000. Disponível em: <http://dx.doi.org/10.1590/S0100204X2000000600022>. Acesso em: 24 jun. 2017.

YANG, L.; PAULSON, A. T. Mechanical and water vapour barrier properties of edible gellan films. Food Research International, San Diego, v. 33, n. 7, p. 563-570, Aug. 2000. Disponível em: <https://doi.org/10.1016/S0963-9969(00)00092-2>. Acesso em: 13 maio 2017. 